\title{
Meltwater produced by wind-albedo interaction stored in an East Antarctic ice shelf
}

\author{
J. T. M. Lenaerts ${ }^{1,2 \star \dagger}$, S. Lhermitte ${ }^{2,3 \dagger}$, R. Drews ${ }^{4 \dagger}$, S. R. M. Ligtenberg ${ }^{1}$, S. Berger $^{4}$, V. Helm ${ }^{5}$, \\ C. J. P. P. Smeets ${ }^{1}$, M. R. van den Broeke ${ }^{1}$, W. J. van de Berg${ }^{1}$, E. van Meijgaard ${ }^{6}$, M. Eijkelboom¹, \\ O. Eisen ${ }^{5,7}$ and F. Pattyn ${ }^{4}$
}

Surface melt and subsequent firn air depletion can ultimately lead to disintegration of Antarctic ice shelves ${ }^{1,2}$ causing grounded glaciers to accelerate ${ }^{3}$ and sea level to rise. In the Antarctic Peninsula, foehn winds enhance melting near the grounding line ${ }^{4}$, which in the recent past has led to the disintegration of the most northerly ice shelves ${ }^{5,6}$. Here, we provide observational and model evidence that this process also occurs over an East Antarctic ice shelf, where meltwaterinduced firn air depletion is found in the grounding zone. Unlike the Antarctic Peninsula, where foehn events originate from episodic interaction of the circumpolar westerlies with the topography, in coastal East Antarctica high temperatures are caused by persistent katabatic winds originating from the ice sheet's interior. Katabatic winds warm and mix the air as it flows downward and cause widespread snow erosion, explaining $>3 \mathrm{~K}$ higher near-surface temperatures in summer and surface melt doubling in the grounding zone compared with its surroundings. Additionally, these winds expose blue ice and firn with lower surface albedo, further enhancing melt. The in situ observation of supraglacial flow and englacial storage of meltwater suggests that ice-shelf grounding zones in East Antarctica, like their Antarctic Peninsula counterparts, are vulnerable to hydrofracturing ${ }^{7}$.

About three-quarters of the Antarctic coastline is fringed by ice shelves ${ }^{8}$, the floating extensions of the grounded ice sheet. These ice shelves regulate Antarctic ice-sheet mass balance by buttressing grounded ice farther upstream ${ }^{9}$. At the interface with the ocean, on average half of the ice mass is lost through basal melting ${ }^{10}$ before calving occurs at the ice-shelf front. For an ice shelf in balance, the mass loss is compensated by mass influx at the grounding line and a positive surface mass balance (SMB) at the shelf-atmosphere interface. The SMB, notably the meltto-accumulation ratio, determines the firn air content (FAC), the amount of pore space in the firn layer ${ }^{2}$. Ice shelves that experience regular surface melt and receive little snowfall have little pore space to accommodate meltwater. Resulting meltwater ponding on the surface makes them prone to hydrofracturing ${ }^{11}$, evidenced by the recent break-up of Larsen A and B ice shelves, in 1995 and 2002, respectively. It is generally assumed that East Antarctic ice shelves have a low melt-to-accumulation ratio, resulting in a high $\mathrm{FAC}^{12}$. Here, we provide evidence of surface meltwater production and firn air depletion along the grounding line of East Antarctic ice shelves.
In January 2015, an airborne survey by the Alfred Wegener Institute observed an approximately $3-\mathrm{km}$-wide circular feature on the Roi Baudouin Ice Shelf, Dronning Maud Land, East Antarctica $\left(24^{\circ}-33^{\circ} \mathrm{E}, 71^{\circ}-69^{\circ} \mathrm{S}\right.$, RBIS hereafter, Fig. 1a). One year later, in January 2016, a field party identified the feature as a 3-m-deep depression in the ice shelf (Fig. 1e) with raised edges and a diagonal fault consisting of 10-m-high ice blocks (Fig. 1g). These point towards the feature being an ice doline ${ }^{13}$, a collapsed cavity in the ice shelf formed by a previously drained meltwater lake. In its centre, three moulins were found to drain water from two well-developed meltwater streams (Fig. 1d,e,g-i and Supplementary Movie 1). The same field team also found multiple other meltwater features along the entire RBIS grounding zone. On the western RBIS, widespread shallow subsurface meltwater ${ }^{14}$ was found in blue-ice areas above the grounding line (Fig. 1c). Farther downstream, shallow ice drilling and radar (Supplementary Fig. 1) revealed multiple englacial lakes several metres under the surface (Fig. If and Supplementary Movie 2), with lake top depth increasing towards the coast (Fig. 1c). These features are suggestive of meltwater production above the grounding line. The meltwater flows downhill onto the ice shelf, where it collects in surface depressions (Fig. 1b) and forms lakes that get buried by new snow, progressively submerging as they are advected towards the calving front. The finding of englacial meltwater storage suggests that meltwater production is more abundant than assumed by the detection of supraglacial water from aeroplanes or satellites ${ }^{15-17}$. Combined analysis of visible (Moderate Resolution Imaging Spectroradiometer (MODIS)), radar satellite imagery and ice-shelf topography (Methods) confirmed the presence of at least 55 supraglacial and englacial lakes in the grounding zone of the RBIS during summer (Fig. 1a).

To explain these meltwater features, we use local meteorological and firn observations retrieved in austral summers 2014-2015 and 2015-2016, complemented by satellite remote sensing and output of the high-resolution (5.5 km grid) climate model RACMO2.3 (see Methods). The sloping ice-sheet topography (100-200 vertical metres per $10 \mathrm{~km}$ ) in the escarpment region south of the RBIS generates strong and directionally persistent katabatic winds (Fig. 2a) with annual mean speeds in excess of $10 \mathrm{~m} \mathrm{~s}^{-1}$ (ref. 18). With a directional constancy exceeding 0.95 (Supplementary Fig. 2), these downslope winds are far more relentless than the episodic foehn events in the grounding zone of Antarctic Peninsula ice shelves $^{5}$, where directional constancy is lower than 0.7. They

\footnotetext{
${ }^{1}$ Institute for Marine and Atmospheric Research Utrecht, Utrecht University, 3584 CC Utrecht, The Netherlands. ${ }^{2}$ Department of Earth and Environmental Sciences, KU Leuven, B-3000 Leuven, Belgium. ${ }^{3}$ Department of Geoscience and Remote Sensing, Delft University of Technology, 2600 GA Delft,

The Netherlands. ${ }^{4}$ Laboratoire de Glaciologie, Université Libre de Bruxelles, B-1050 Brussels, Belgium. ${ }^{5}$ Alfred Wegener Institute, D-27568 Bremerhaven, Germany. ${ }^{6}$ Royal Netherlands Meteorological Institute, 3730 AE De Bilt, The Netherlands. ${ }^{7}$ Department of Geosciences, University of Bremen, D-28359 Bremen, Germany. ${ }^{\dagger}$ These authors contributed equally to this work. "Present address: Bavarian Academy of Sciences and Humanities, D-80539 München, Germany. *e-mail: jtmlenaerts@gmail.com
} 
Latitude $\left({ }^{\circ} \mathrm{S}\right)$

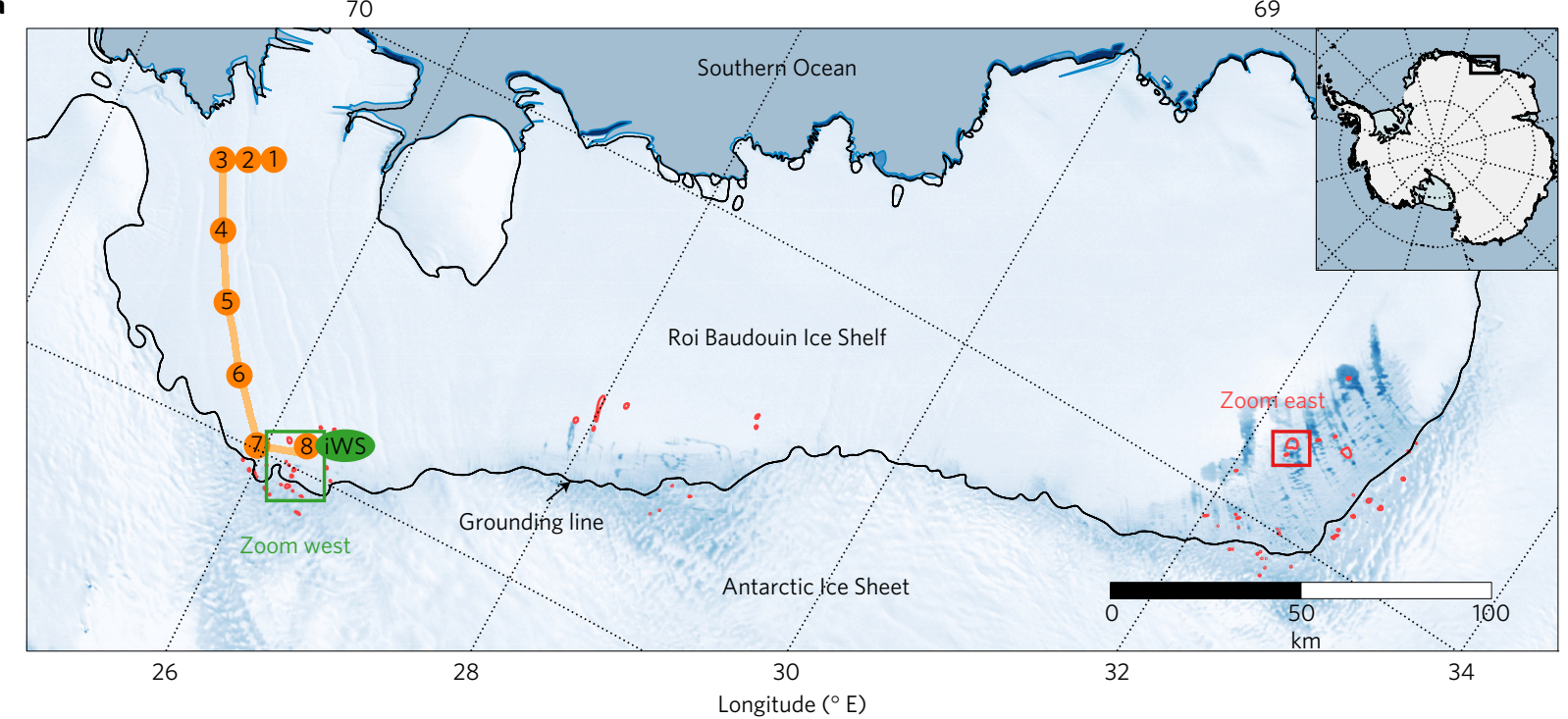

b
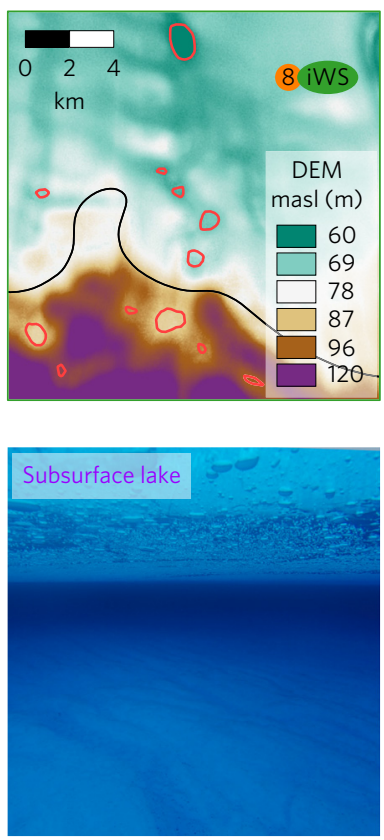

C
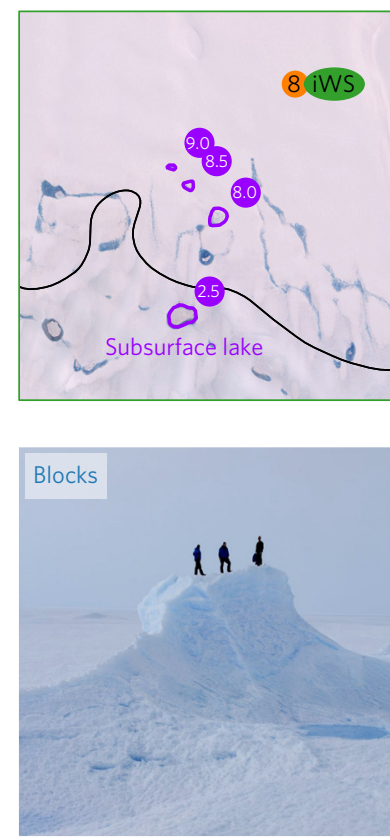

d

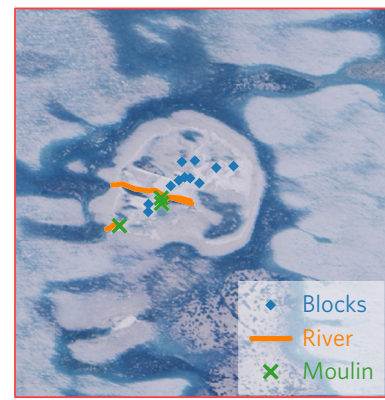

h

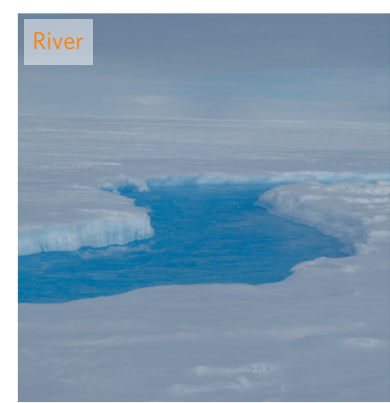

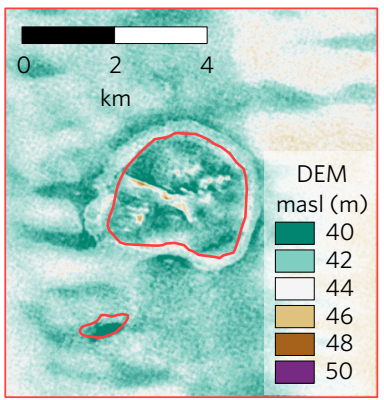

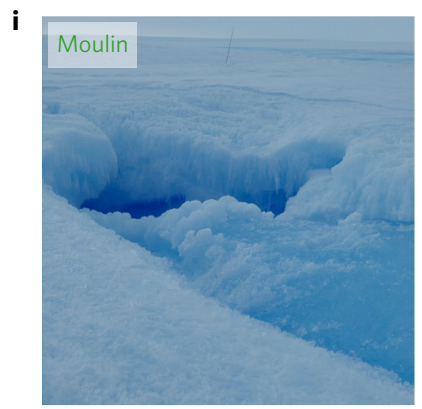

Figure 1 | Meltwater features on the RBIS. a, Overview map with MODIS mosaic ${ }^{22}$ in the background. Meltwater lakes are delineated in red (see

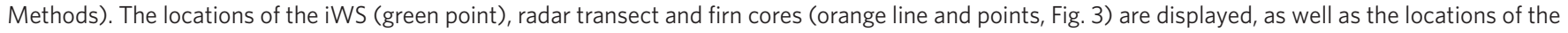
two enlarged regions in $\mathbf{b}-\mathbf{e}$. The grounding line definition is taken from ref. 10. b-e, Enlarged regions in the western (b,c) and eastern RBIS grounding

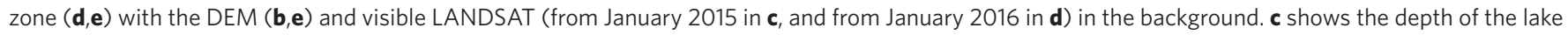
surface as detected by coring and radar surveys, which increases away from the grounding line. For example, the depth difference of the lake above the grounding line and the nearest lake ( $5.5 \mathrm{~m}$ over a horizontal distance of $4 \mathrm{~km}$ ) is consistent with the observed ice velocity ( $\sim 170 \mathrm{~m}$ per year) and SMB ( $\sim 30 \mathrm{~cm}$ snow per year). f-i, Images of meltwater features identified on the RBIS, all obtained in January and February 2016 : (f) englacial water storage (refer to Supplementary Movie 1 for additional footage); (g-i) ice blocks, meltwater river, and moulins as seen in the doline (refer to Supplementary Movie 2 for additional footage).

generate the atmospheric and surface conditions that are responsible for the meltwater production in the RBIS grounding zone in two ways. Firstly, the downslope winds disrupt the surface-based temperature inversion, efficiently increasing temperatures and decreasing relative humidity. Summer near-surface temperatures are significantly higher ( $>3 \mathrm{~K}$, Fig. $2 \mathrm{a}$ ) near the grounding zone than towards the calving front, approximately $50 \mathrm{~km}$ downstream, where the surface-based temperature inversion prevails. This regional warming doubles the surface meltwater production when compared with the region farther downstream, as derived by microwave radar backscatter ${ }^{19}$. Secondly, the strong near-surface winds have the potential to erode the snow surface ${ }^{20}$. Continuous wind scouring ${ }^{21}$ in the RBIS grounding zone exposes highly compacted, large-grained snow $^{22}$ or even blue ice at the surface. The latter is characterized by albedo values $(\sim 0.57)$ that are significantly lower than for refrozen snow $(\sim 0.7)$ (Fig. 2b).

Both the melting of snow and the exposure of blue ice enhance the absorption of short-wave radiation and hence melt rates. An estimate of the impact of surface darkening on melt rate can be obtained by lowering the summer surface albedo at the weather 
a

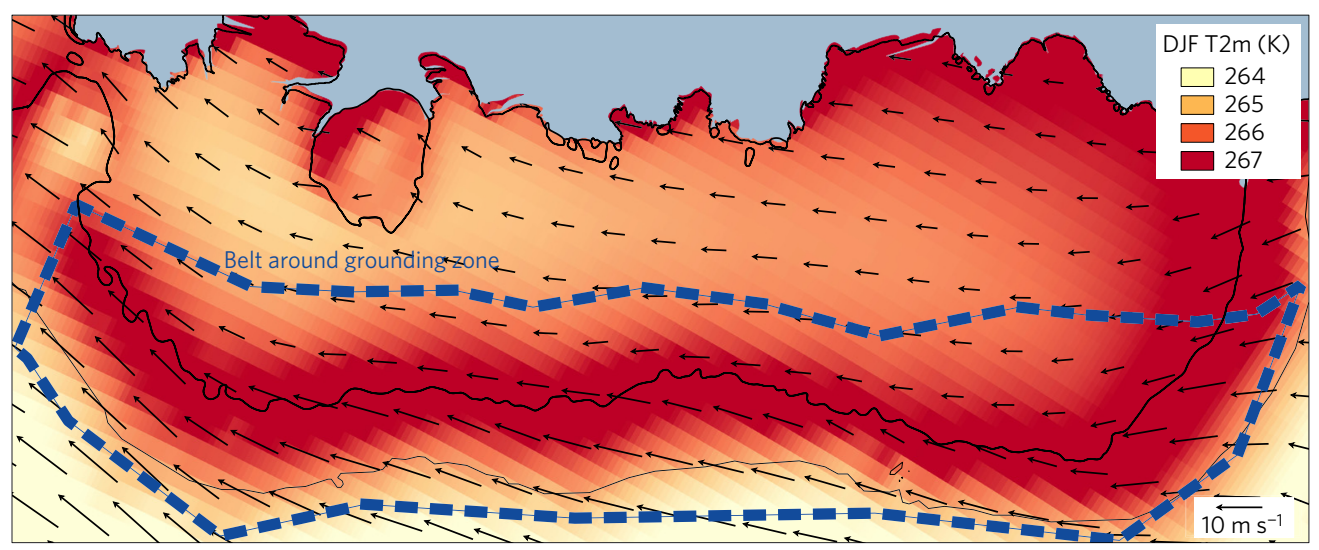

b
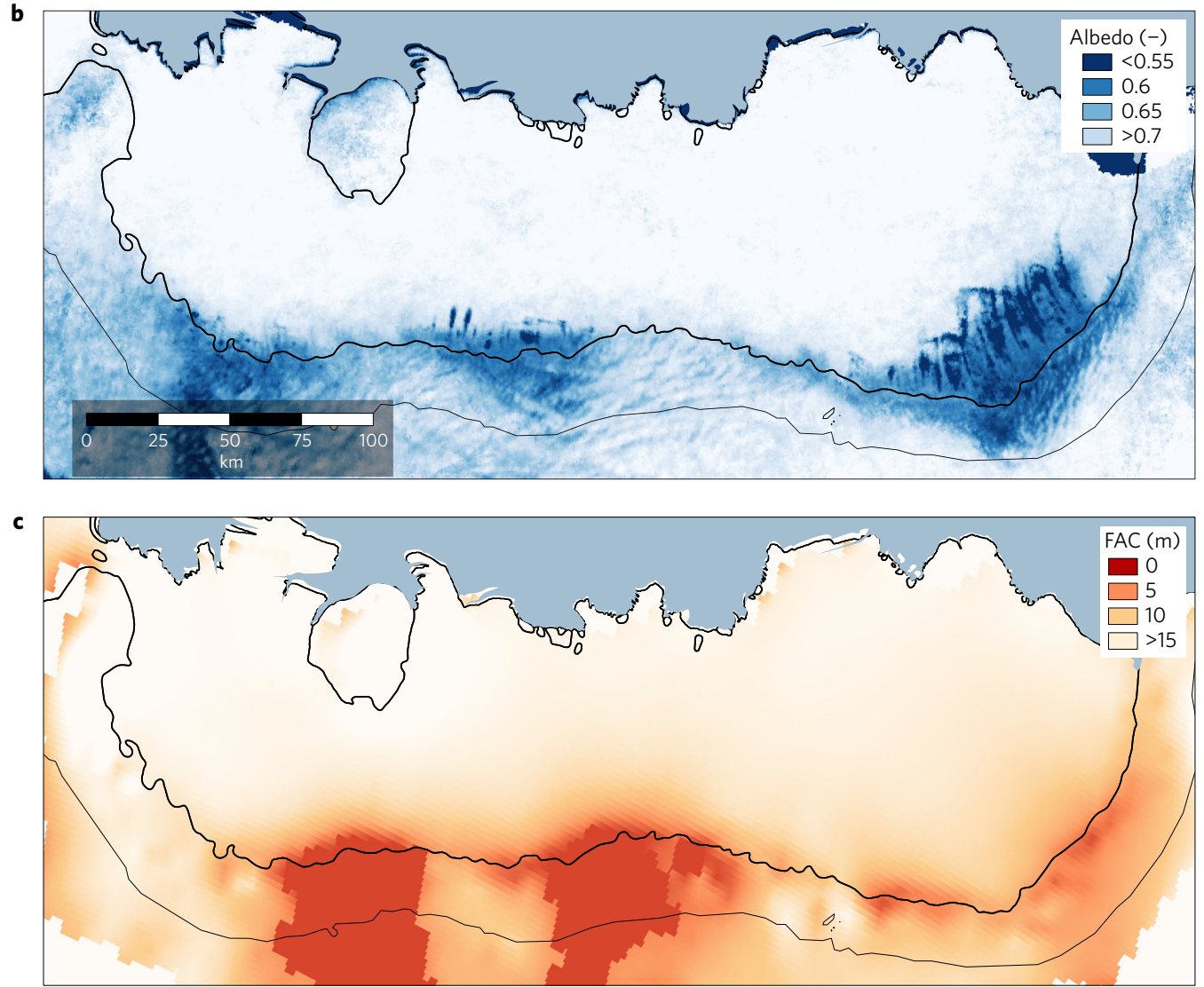

Figure 2 | Summer near-surface climate and surface conditions of the RBIS. a, Simulated 1979-2015 mean summer (December, January, February (DJF)) near-surface temperature (colours) and near-surface wind speed (vectors). b, Summer albedo (lowest 5\% percentile value) derived by MODIS imagery. c, Mean FAC for the period 1979-2015. FAC equals the total air content of the firn layer (that is, the vertically integrated difference between the ice density and the actual density), and is expressed as the thickness of the equivalent air column contained in the firn in metres. The extent of the grounding zone for which the surface melt was calculated (Supplementary Fig. 5) is drawn with the dashed blue line in a.

station site from the measured value to that of blue ice, while at the same time retaining the observed atmospheric forcing in the surface energy balance model (see Methods). As a result, surface melt almost quadruples in both summer seasons (Supplementary Fig. 3). This illustrates that surface melt in the RBIS grounding zone is strongly controlled by short-wave radiation availability and the melt-albedo feedback. A RACMO2.3 post-calibration of melt rate using MODIS albedo allows one to estimate total meltwater production around the RBIS grounding zone (blue dashed line in Fig. 2a) from 1979 to 2015 (Supplementary Fig. 4 and 5). We find strong inter-annual variability $\left(2.2 \pm 1.9 \mathrm{~km}^{3}\right.$, mean \pm s.d. $)$, with cold summers producing negligible melt and warm summers producing up to $6 \mathrm{~km}^{3}$ of meltwater.
To determine FAC over the RBIS, we use a time-dependent firn densification model (IMAU-FDM, see Methods) driven by near-surface meteorological conditions simulated with RACMO2.3. Figure $2 \mathrm{c}$ shows that FAC is less than $10 \mathrm{~m}$ in the entire RBIS grounding zone, with values close to zero in low-SMB regions. In contrast, FAC exceeds $15 \mathrm{~m}$ on the remainder of the RBIS, which is a relatively high value for East Antarctic ice shelves ${ }^{12}$. This remarkable FAC gradient on the RBIS is supported by snow density observations from shallow cores (Fig. 3), drilled along a transect from the coast upstream in December 2014 (Methods). The downstream cores show low-density winter firn alternating with shallow ice-containing layers ( $<10 \mathrm{~cm}$ thick). However, RBIS cores 7 and 8, both located within $10 \mathrm{~km}$ from the grounding line, 


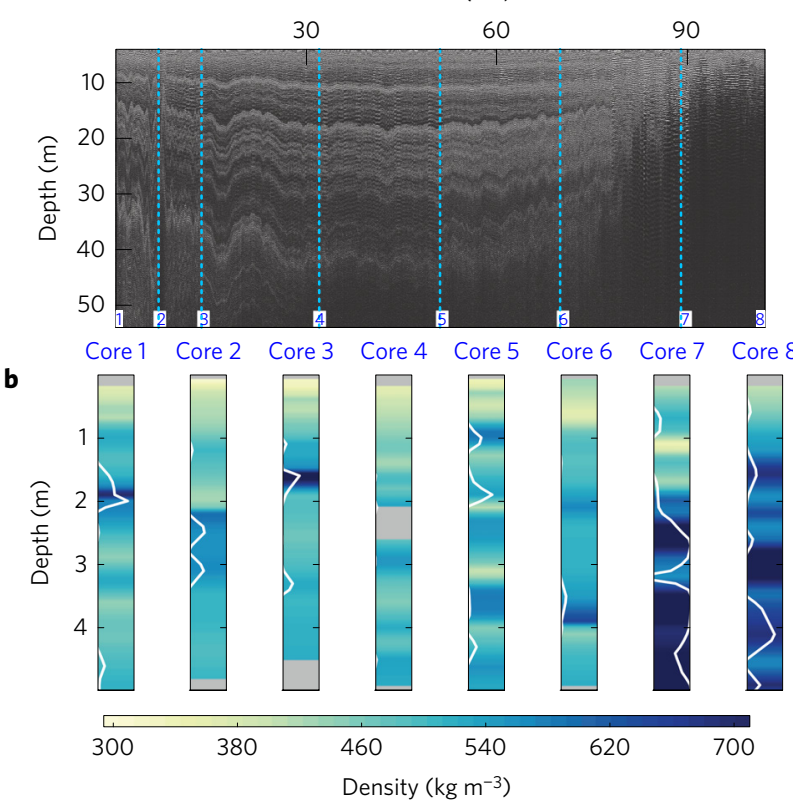

Figure $\mathbf{3}$ | Measured firn conditions over the RBIS. a, Radar-derived firn structure along the transect across the RBIS (Fig. 1). Bright colours indicate strong reflectivity. Depth is approximated using a constant wave speed in firn. The vertical blue lines show the location of each firn core (see number above) in $\mathbf{b}$ along the transect. b. Measured firn density (colours) and ice content (white lines); scale ranges from $0 \%$ ice (left) to $100 \%$ ice (right) derived from the cores along the same RBIS transect. See Fig. 1 for location of the cores.

show a shallow winter firn pack on top of thick layers of refrozen, high-density firn $\left(>650 \mathrm{~kg} \mathrm{~m}^{-3}\right)$ that extend down to at least $8 \mathrm{~m}$ depth in RBIS core 8 (not shown). The rapid transition from high to low FAC values is further supported by $400 \mathrm{MHz}$ groundpenetrating radar observations along the same transect (Fig. 3). The 105-km-long radar transect shows multiple, horizontally coherent, internal reflection horizons for about $80 \mathrm{~km}$. Then, over a horizontal distance of only a few kilometres, all horizons slope upwards to the surface. For a $25-\mathrm{km}$-long interval near the grounding line, no reflection horizons are evident. This is consistent with surface melt and internal refreezing, which obliterate the annual layering. The low FAC in the RBIS grounding zone impacts not only the firn structure, but also the characteristics of the RBIS: compared with currently established values ${ }^{10}$, ice-shelf thickness is $50-100 \mathrm{~m}$ larger when using the high-resolution RACMO2.3 output, which in turn increases solid ice flux at the grounding line $e^{23}(10-20 \%$, not shown) and regional basal melting (1-3 $\mathrm{m} \mathrm{yr}^{-1}$ or $\left.20-60 \%\right)$ (Supplementary Fig. 6).

We showed that regionally enhanced temperatures and reduced albedo through wind scouring result in extensive meltwater production, drainage and storage near the grounding line of the RBIS. Although supraglacial melt features on East Antarctic ice shelves have been reported before ${ }^{15-17}$, this is the first time that englacial storage is observed and a connection is made with upstream climate conditions (katabatic winds and blue ice). Meltwater warms the ice-shelf firn and ice by latent heat release when it refreezes englacially, and enhances basal melting rates when it enters the sub-shelf cavity, where it potentially affects stratification and sub-shelf circulation ${ }^{24}$. Dolines found at the surface of RBIS and other East Antarctic ice shelves ${ }^{15,17}$ indicate that at some point lake drainage will occur ${ }^{25}$. Additional satellite imagery (Fig. 4) shows that similar surface melt 'hotspots' are widespread in the grounding zones of ice shelves to the west (for example, Fimbul and Nivl ice shelves) and east (Amery Ice Shelf). Like at the RBIS, these are adjacent to wind-induced blue-ice areas on the grounded ice ${ }^{26}$, confirming the close interaction between upstream wind scouring, albedo, meltwater production and firn air depletion. East Antarctic ice shelves, especially those that are relatively thin, are therefore likely to exhibit the same sensitivity to hydrofracturing as their counterparts in the Antarctic Peninsula.

Historical visible satellite imagery (Supplementary Fig. 7) and climate model output demonstrate that surface melt has occurred on the RBIS since the start of the observational record (1980s), but only during warm summers. No trend is visible over this period (Supplementary Fig. 5). The high correlation between regional nearsurface summer temperature and melt $\left(R^{2}=0.7\right.$, Supplementary Fig. 5) suggests that meltwater production and subsequent storage and drainage will increase in the future, when warm summers are projected to be more prevalent ${ }^{27}$. In combination with constant katabatic winds ${ }^{28}$, this would further deplete firn pore space near these grounding lines, amplifying the risk of ice-shelf collapse and subsequent rapid ice loss from East Antarctica?

\section{Methods}

Methods, including statements of data availability and any associated accession codes and references, are available in the online version of this paper.

Received 16 June 2016; accepted 9 November 2016; published online 12 December 2016
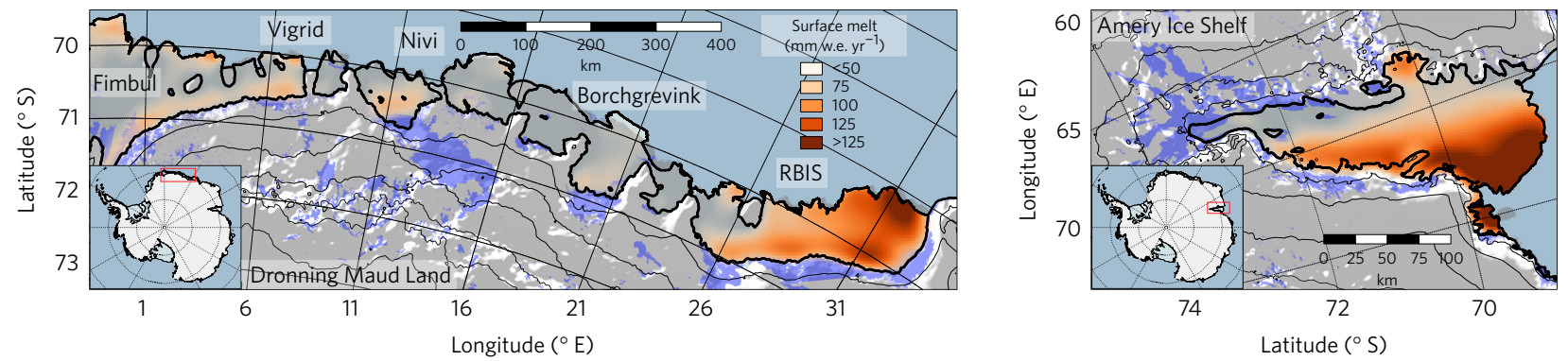

Figure 4 | Surface meltwater features in East Antarctica. Surface melt volume derived from QuickScat scatterometer (2000-2009 average) ${ }^{19}$ (red colours) and blue-ice cover ${ }^{29}$. The grounding line and coastline are represented by the thick black line. Background is the grey-shaded MODIS Mosaic of Antarctica (MOA) which is made transparent where the mean surface slope in the wind direction (MSWD $)^{21,26}$ exceeds 0.1. The spatial co-occurrence of high MSWD and blue ice upstream of East Antarctic ice shelves indicates that the latter exists because of strong wind scouring. The total overlapping area of intense wind-albedo interaction, that is, high MSWD and blue ice beneath $500 \mathrm{~m}$ elevation over Antarctica equals about $67,000 \mathrm{~km}^{2}$ (Supplementary Fig. 8), which is about $26 \%$ and $73 \%$ of the area of high MSWD and blue-ice area below $500 \mathrm{~m}$, respectively. Melt rates are underestimated in these areas, because the surface melt volume is derived from the backscatter signal over a snow surface ${ }^{19}$. Supplementary Fig. 8 indicates that surface melt is strongly enhanced over blue-ice areas when including the albedo feedback. 


\section{References}

1. Van den Broeke, M. R. Strong surface melting preceded collapse of Antarctic Peninsula ice shelf. Geophys. Res. Lett. 32, 1-4 (2005).

2. Kuipers Munneke, P., Ligtenberg, S. R. M., Van Den Broeke, M. R. \& Vaughan, D. G. Firn air depletion as a precursor of Antarctic ice-shelf collapse. J. Glaciol. 60, 205-214 (2014).

3. Rignot, E. et al. Accelerated ice discharge from the Antarctic Peninsula following the collapse of Larsen B ice shelf. Geophys. Res. Lett. 31, L18401 (2004).

4. Hubbard, B. et al. Massive subsurface ice formed by refreezing of ice-shelf melt ponds. Nat. Commun. 7, 11897 (2016)

5. Cape, M. R. et al. Foehn winds link climate-driven warming to ice shelf evolution in Antarctica. J. Geophys. Res. 120, 11037-11057 (2015).

6. Luckman, A. et al. Surface melt and ponding on Larsen C Ice Shelf and the impact of Föhn winds. Antarct. Sci. 26, 625-635 (2014).

7. Pollard, D. \& Deconto, R. M. Contribution of Antarctica to past and future sea-level rise. Nature 531, 591-597 (2016)

8. Bindschadler, R. et al. Getting around Antarctica: new high-resolution mappings of the grounded and freely-floating boundaries of the Antarctic ice sheet created for the International Polar Year. Cryosphere 5, 569-588 (2011)

9. Fürst, J. J. et al. The safety band of Antarctic ice shelves. Nat. Clim. Change 6 , 2014-2017 (2016).

10. Depoorter, M. A. et al. Calving fluxes and basal melt rates of Antarctic ice shelves. Nature 502, 89-92 (2013)

11. Banwell, A. F., MacAyeal, D. R. \& Sergienko, O. V. Breakup of the Larsen B ice shelf triggered by chain reaction drainage of supraglacial lakes. Geophys. Res. Lett. 40, 5872-5876 (2013)

12. Ligtenberg, S. R. M., Kuipers Munneke, P. \& Van den Broeke, M. R. Present and future variations in Antarctic firn air content. Cryosphere 8, 1711-1723 (2014).

13. Macayeal, D. R. \& Sergienko, O. V. The flexural dynamics of melting ice shelves. Ann. Glaciol. 54, 1-10 (2013).

14. Liston, G. E., Winther, J. G., Bruland, O., Elvehøy, H. \& Sand, K. Below-surface ice melt on the coastal Antarctic ice sheet. J. Glaciol. 45, 273-285 (1999).

15. Phillips, H. A. Surface meltstreams on the Amery Ice Shelf, East Antarctica. Ann. Glaciol. 27, 177-181 (1998).

16. Kingslake, J., Ng, F. \& Sole, A. Modelling channelized surface drainage of supraglacial lakes. J. Glaciol. 61, 185-199 (2015).

17. Langley, E. S., Leeson, A. A., Stokes, C. R. \& Jamieson, S. S. R. Seasonal evolution of supraglacial lakes on an East Antarctic outlet glacier. Geophys. Res. Lett. 43, 8563-8571 (2016).

18. Lenaerts, J. T. M. et al. High variability of climate and surface mass balance induced by Antarctic ice rises. J. Glaciol. 60, 1101-1110 (2014).

19. Trusel, L. D., Frey, K. E., Das, S. B., Kuipers Munneke, P. \& Van den Broeke, M. R. Satellite-based estimates of Antarctic surface meltwater fluxes. Geophys. Res. Lett. 40, 6148-6153 (2013).

20. Lenaerts, J. T. M. \& Van den Broeke, M. R. Modeling drifting snow in Antarctica with a regional climate model: 2. Results. J. Geophys. Res. 117, D05108 (2012).

21. Das, I. et al. Influence of persistent wind scour on the surface mass balance of Antarctica. Nat. Geosci. 6, 367-371 (2013).

22. Scambos, T. A., Haran, T. M., Fahnestock, M. A., Painter, T. H. \& Bohlander, J. MODIS-based Mosaic of Antarctica (MOA) data sets: continent-wide surface morphology and snow grain size. Remote Sens. Environ. 111, 242-257 (2007).

23. Callens, D. et al. Mass balance of the Sør Rondane glacial system, East Antarctica. Ann. Glaciol. 56, 63-69 (2015).
24. Le Brocq, A. M. et al. Evidence from ice shelves for channelized meltwater flow beneath the Antarctic Ice Sheet. Nat. Geosci. 6, 945-948 (2013).

25. Banwell, A. F. \& Macayeal, D. R. Ice-shelf fracture due to viscoelastic flexure stress induced by fill/drain cycles of supraglacial lakes. Antarct. Sci. 27, 587-597 (2015)

26. Scambos, T. A. et al. Extent of low-accumulation 'wind glaze' areas on the East Antarctic plateau: implications for continental ice mass balance. J. Glaciol. 58, 633-647 (2012).

27. Lenaerts, J. T. M., Vizcaino, M., Fyke, J., Kampenhout, L. \& van den Broeke, M. R. Present-day and future Antarctic ice sheet climate and surface mass balance in the Community Earth System Model. Clim. Dynam. 47, 1367-1381 (2016)

28. Van den Broeke, M. R., van de Wal, R. S. W. \& Wild, M. Representation of Antarctic katabatic winds in a high-resolution GCM and a note on their climate sensitivity. J. Clim. 10, 3111-3130 (1997).

29. Hui, F. et al. Mapping blue-ice areas in Antarctica using ETM+ and MODIS data. Ann. Glaciol. 55, 129-137 (2014).

\section{Acknowledgements}

Field data were collected in the framework of the BENEMELT project, in collaboration with the BELSPO project ICECON. BENEMELT benefits from the InBev-Baillet Latour Antarctica Fellowship, a joint initiative of the InBev-Baillet Latour Fund and the International Polar Foundation (IPF) that aims to promote scientific excellence. We gratefully acknowledge field support from IPF, BELSPO, AntarctiQ, the Belgian Polar Secretariat and the Belgian military. We thank G. Eagles, T. Binder and C. Müller from the Alfred Wegener Institute, who first discovered the circular melt feature in 2015. This study is partly funded by Utrecht University through its strategic theme Sustainability, sub-theme Water, Climate \& Ecosystems. This work was carried out under the programme of the Netherlands Earth System Science Centre (NESSC), financially supported by the Ministry of Education, Culture and Science (OCW). J.T.M.L. is supported by NWO ALW through a Veni postdoctoral grant. S.L. was supported as a post-doc by FWO. R.D. was funded by the FNRS Project MEDRISSM and partial support by the Deutsche Forschungsgmeinschaft with a grant SPP 'Antarctic Research' MA 3347/10-1. Analysis and graphics are made using QGIS package Quantarctica, and the NCAR Command Language (http://dx.doi.org/10.5065/D6WD3XH5). TanDEM-X SLC data were provided by the German Space Agency (DLR) within the proposal ATI_GLAC0267.

\section{Author contributions}

J.T.M.L. and S.L. contributed equally to this work. J.T.M.L. conceived the study, led the first field season with support from F.P., performed climate simulations with support from W.J.v.d.B., E.v.M. and M.R.v.d.B. and wrote an initial version of the paper. S.L. led the second field season, with support from R.D. and M.E. and was responsible for the remote sensing analyses. R.D. analysed the GPR data. S.R.M.L. was responsible for the firn model simulations. S.B. compiled the ALOS data and the RBIS thickness and basal melting data sets. C.J.P.P.S. performed quality control of the weather station observations. V.H. and O.E. provided a first analysis of the circular melt feature and provided the high-resolution TanDEM-X DEM. All authors contributed to the writing of the manuscript.

\section{Additional information}

Supplementary information is available in the online version of the paper. Reprints and permissions information is available online at www.nature.com/reprints.

Correspondence and requests for materials should be addressed to J.T.M.L.

\section{Competing financial interests}

The authors declare no competing financial interests. 


\section{Methods}

Climate and firn models. We use output from the high-resolution $(5.5 \mathrm{~km}$ horizontal gridding) regional atmospheric climate model RACMO, version 2.3 (ref. 18), with a spatial domain focused on Dronning Maud Land $\left(\sim 25^{\circ} \mathrm{W}-\sim 45^{\circ} \mathrm{E}\right)$ in East Antarctica. RACMO2.3 is forced at its lateral boundaries by atmospheric profiles, and at its surface boundaries by sea-surface temperatures and sea-ice extent from the ERA-Interim reanalysis from the European Centre for Medium-range Weather Forecasts (ECMWF, 1979-2015). RACMO2.3 freely evolves in its inner spatial domain, including the snow/ice pack. At the employed resolution, the model is able to represent observed regional variability in climate and SMB surface climate over the RBIS ${ }^{18}$. Simulated near-surface wind speed, which drives the drifting snow processes that lead to firn scouring in the RBIS grounding zone, compares well $\left(R^{2}>0.95\right)$ to the observed wind speed in summer 2014-2015 (Supplementary Fig. 9). To derive firn air content, three-hourly RACMO2.3 SMB and surface temperatures are used as forcing for a transient run with a firn densification model (IMAU-FDM) ${ }^{30}$ that allows for meltwater percolation, retention and refreezing in the firn.

Weather station data and derivation of surface melt. A new-generation, light-weight automatic weather station (iWS) was installed in the grounding zone of the RBIS on 10 December 2014 and dismantled $\sim 14$ months later (3 February 2016). The station collected continuous observations of atmospheric temperature and humidity, wind speed, incoming and outgoing short-wave and long-wave radiation components, snow height variations, and firn temperatures. The iWS employs an air temperature sensor inside a radiation screen and an open-air mounted thermocouple. The former typically overestimate temperature in strong radiation and low wind speed conditions. On the other hand, the thin wire thermocouple ( $0.08 \mathrm{~mm}$ thickness) is barely affected by such a temperature bias and is used as a reference to develop dedicated air temperature corrections for the other temperature sensors inside the iWS. A small digital humidity and temperature sensor is placed underneath the iWS housing and inside a filter cap for protection from contamination, but without radiation protection. The temperature difference inside and outside the cap is used to obtain a radiation-corrected value of relative humidity.

The corrected data were used as input for a surface energy balance model ${ }^{31}$ that uses a bulk method to calculate turbulent heat and moisture exchange, subsurface absorption of heat and observed radiation components to derive surface melt volume, assuming surface energy balance closure. The model-derived surface temperature compares very well to the observed surface temperature $\left(R^{2}>0.99\right)$, confirming the validity of this approach. To test the sensitivity of surface melt to surface albedo (Supplementary Figs 3-5), we used the atmospheric input of the iWS, but replaced the measured albedo values by the satellite-derived albedo values of the blue-ice fields nearby $(0.57 \pm 0.02$, Fig. $2 b)$. The satellite albedo values were derived from the MODIS MCD43A3 product white-sky albedo product, describing the 16-day albedo on a $500 \mathrm{~m}$ spatial resolution from multi-angle observations, where the $5 \%$ lowest albedo was chosen to represent the multi-year blue-ice albedo. This $5 \%$ approach is based on the assumption that, when blue ice is exposed in summer, its albedo corresponds to the lower percentiles of the albedo distribution, while it omits outliers that are considered measurement errors ${ }^{32}$. In a similar fashion, we adjusted the modelled surface albedo in the RBIS grounding zone: for each grid point and days with simulated surface melt, we replaced the modelled albedo by the MODIS albedo and scaled the surface melt according to the ratio between RACMO2.3 and MODIS albedo, under the assumption that all additional short-wave energy is consumed by surface melt.

Firn density. Firn density and ice content were measured in firn cores drilled manually with a 9-cm-diameter Kovacs ice drill. Firn coring was performed in a shaded location or during low-sun conditions to prevent snow melting during the measurement. In the field, the diameter and length (varying between 10 and $100 \mathrm{~cm}$ ) of each core segment was measured manually. The mass was determined with high-precision ( $1 \mathrm{~g}$ accuracy) weighing scales. Depth and thickness of ice lenses were identified visually. Using a typical measurement error in diameter of $0.3 \mathrm{~cm}$ and in length of $1 \mathrm{~cm}$, each firn core density measurement is associated with a $\sim 10 \%$ uncertainty (neglecting mass uncertainty). The ice content per core is defined as the cumulative length of ice layers found in each core segment divided by its total length.

Ground-penetrating radar. The ground-penetrating radar profile on RBIS was collected in December 2014 using a commercial $400 \mathrm{MHz}$ antenna. The north-south transect along RBIS was positioned parallel to ice-shelf channels to avoid a disruption of the internal reflection horizon (IRH) geometry. An exception is the transect between core 1-3, which crosses an ice-shelf channel in across-flow direction with correspondingly disrupted $\mathrm{IRHs}^{33}$. For the travel time to depth conversion, we assume a constant density with depth ${ }^{18}$, a reasonable approximation for the transect between core 1 and core 6 , but less so between core $6-8$. However, sensitivity tests show that the overall IRH geometry with the steep IRH gradient near core 6 and the absence of IRHs at cores 7 and 8 is not sensitive to the choice of travel time-depth conversion.

Lake and elevation mapping. The meltwater lakes were delineated manually, using a combination of visible Landsat imagery and high-resolution $(\sim 6.25 \mathrm{~m})$ geo-referenced amplitude images from the L-band Synthetic Aperture Radar sensor (PALSAR) onboard ALOS satellite (level 1.5 of the Fine Beam Single polarization mode). L-band radar is ideally suited for detection of surface and buried meltwater lakes ${ }^{34}$. The radar images we selected date back from the 2010-2011 summer season, an average melt season (Supplementary Fig. 5). The digital elevation model (DEM) is constructed using TanDEM-X data, with a horizontal resolution of $10 \mathrm{~m}$ and a relative vertical accuracy of better then $1 \mathrm{~m}$, estimated as the standard deviation of the difference of overlapping frames.

Data availability. The MODIS Mosaic of Antarctica (Fig. 4) is available from the National Snow and Ice Data Center (NSIDC, https://nsidc.org/data/moa). MODIS imagery for the surface albedo calculations were downloaded from via NASA GSFC (https://modis.gsfc.nasa.gov), and LANDSAT imagery via the USGS EarthExplorer (http://earthexplorer.usgs.gov). PALSAR data are available via the Alaska Satellite Facility website (https://vertex.daac.asf.alaska.edu). The high-resolution DEM from TanDEM-X is available for use via https://doi.org/10.1594/PANGAEA.868109. The climate model, firn model, and field observations are available from the corresponding author on request.

\section{References}

30. Ligtenberg, S. R. M., Helsen, M. M. \& Van den Broeke, M. R. An improved semi-empirical model for the densification of Antarctic firn. Cryosphere 5, 809-819 (2011)

31. Kuipers Munneke, P., Van den Broeke, M. R., King, J. C., Gray, T. \& Reijmer, C. H. Near-surface climate and surface energy budget of Larsen C ice shelf, Antarctic Peninsula. Cryosphere 6, 353-363 (2012).

32. Van Angelen, J. H. et al. Sensitivity of Greenland Ice Sheet surface mass balance to surface albedo parameterization: a study with a regional climate model. Cryosphere 6, 1175-1186 (2012)

33. Drews, R. Evolution of ice-shelf channels in Antarctic ice shelves. Cryosphere 9 , 1169-1181 (2015).

34. Koenig, L. S. et al. Wintertime storage of water in buried supraglacial lakes across the Greenland Ice Sheet. Cryosphere 9, 1333-1342 (2015). 